\title{
NOTAS AO USO DE MARCAS DE CERTIFICAÇÃO
}

Giovanne Henrique Bressan Schiavon*

SUMÁRIO: 1. Introdução. 2. Direto Econônico Ambiental. 2.1 Regulação direta. 2.2 Instrumentos Econômicos. 3. Marcas de Certificação. 3.1 ISSO 14000. 4. Conclusão. 5. Bibliografia.

SUMMARY: 1. Introduction. 2. Economic Law and Enviroment. 2.1 Direct regulatory approach. 2.2 Economic instruments. 3. Certification marks. 3.1 ISO 14000. 4. Conclusion. 4. Bibliography.

SUMARIO: 1. Introducción. 2. La Ley Económica y Desenvolvimento. 2.1 Regulación Directa. 2.2 Instrumentos Económicos. 3. La Marca del Certificación. 3.1 ISO 14000. 4. Conclusión. 4. Bibliografía.

RESUMO: Analisa o argumento de que a marca de certificação é um instrumento que pode ser utilizado pelo Estado para induzir a auto regulamentação da atividade econômica.

ABSTRACT: It analyzes the argument of that certification matk is an instrument, that can be used by the State to induce the auto regulation of the economic activity.

RESUMEN: Analiza el argumento de que la marca de la certificación es un instrumento, eso puede ser utilizado por el Estado para inducir la regulación del auto de la actividad económica.

PALAVRAS-CHAVE: Propriedade Intelectual; Direito Econômico; Direito Ambiental; ISO 14000.

KEY-WORDS: Intellectual Property Law; Economic Law; Enviromental Law; ISO 14000 .

PALABRAS-LLAVES: La Propiedad Intelectual; La Ley Económica; Direito Ambiental; ISO 14000.

\footnotetext{
* Mestre en Direito Negocial pela Universidade Estadual de Londrina. Professor Convidado do Curso de Especialização em Filosofia Política e Jurídica da Universidade Estadual dc Londrina. Professor do Curso de Graduação em Direito da Faculdadc Paranaense (FACCAR) em Rolândia - Paraná. E-mail: schiavon_lda@yahoo.com.br
} 


\section{Introducão}

O Estado, expressão do poder político organizado, seleciona e atua por meio de normas que aliviam os particulares da decisão de qual é a conduta socialmente adequada. Se ser soberano significava possuir, de modo absoluto, essa capacidade de elaborar leis e desfrutar do monopólio do uso da força. $\mathrm{Na}$ atualidade, o Estado vê diluir seu poder disciplinador da sociedade.

Nota-se que, a sociedade, cada vez mais, exige a produção de normas aptas a regular a exploração dos recursos naturais. A partir de meados do século XX o modelo de desenvolvimento econômico passa a ser questionado, uma vez que, se toda a população mundial consumisse o que os países desenvolvidos consomem vislumbrar-se-ia uma situação ambiental crítica.

Desde então, princípios e regras foram desenvolvidos para que os empreendimentos de diversos setores da economia atingissem um padrão de gestão que reduzisse desperdícios e minimizasse os impactos sobre o meio ambiente. De sorte a que, os empreendimentos produzam (ou forneçam serviços) em maior quantidade e com melhor qualidade, utilizando menos recursos ambientais.

Isso se dá através da ação de grupos civis (organizações não governamentais - ONGs) paralelamente às instituições governamentais e de iniciativa privada, os quais dentre outras atividades administram marcas de certificação que, além de auxiliar a preservação do meio ambiente, têm por objetivo levar os consumidores a adquirir produtos "ecologicamente corretos".

O presente estudo divide-se em duas partes: na primeira apresenta-se noção de direito econômico ambiental, para na segunda parte questionar especificamente sobre a utilização de marca de certificação no Brasil.

\section{Direito Econômico Ambiental}

A partir do momento que a sociedade internacional começa a perceber a necessidade de padröes de conduta que assegurem o desenvolvimento sustentável, resta a essa duas opções: ou a).- selecionar e impor essas condutas; ou, b).-esperar que os próprios agentes por si tomem consciência de seu papel.

Assim, o exercício do poder normativo no sentido de corrigir os efeitos externos negativos das atividades econômicas em relação à qualidade do 
meio ambiente pode ser exercido em duas perspectivas: pública ou privada.

Da teoria geral do direito extrai-se que uma relação jurídica sempre se refere à disciplina de um interesse. De modo que numa relação de direito privado as partes interessadas contratam a partir do recíproco reconhecimento de que são iguais, melhor dizendo, parte-se de que ambas são autônomas e fazem o melhor para si.

Se numa relação de direito privado compete ao Estado simplesmente garantir o cumprimento do pactuado, numa relação de direito público a atuação estatal é de outra ordem. Nessa o Estado aparece em posição eminente, institucional, ou seja manifestando a sua autoridade.

Grandes acidentes ecológicos, tais como o do navio Exxon Valdez, e a percepção de que um meio ambiente equilibrado é fundamental para a vida humana, conduziram a elaboração de um novo grupo de princípios para os comportamentos das pessoas. De sorte que a sociedade em conjunto com o Estado assumiu que a regulamentação das atividades econômicas é necessária para melhorar a alocação dos recursos ${ }^{2}$.

Neste contexto, em 1972, a Organização das Nações Unidas (ONU) promoveu em Estocolmo uma Conferência para discussão dos problemas do meio ambiente e homem, a qual reuniu 113 países e 250 organizações governamentais e não governamentais e teve como resultado a Declaração sobre o Meio Ambiente Humano.

Essa Declaração incluiu o "Plano de Ação para o Meio Ambiente" e uma lista de princípios, comportamentos e responsabilidades que deveriam governar as decisões concernentes com as questôes ambientais. Seguiram-se, nos diversos países, o aparecimento de vários instrumentos institucionais, legislações e regulamentações para tratar dos problemas decorrentes do desequilíbrio ecológico e da sua preservação ${ }^{3}$.

Vinte anos depois, foi realizada em junho, a Rio-92, a Conferência das Naçóes Unidas sobre Meio Ambiente e Desenvolvimento Humano, no Rio de Janeiro, a qual, reuniu legisladores, diplomatas, cientistas, a mídia, e representantes de organizações não-governamentais (ONGs) de 179 países, num esforço maciço para reconciliar as interações entre o desenvolvimento humano e o meio ambiente.

\footnotetext{
?BRUNDTLAND, Gro Harlen. Desafios Ambientais dos anos 90 . Nossa Responsabilidade para as futuras geraçoes. Trad. Yuri Frederico Dutra. Revisăo técnica Giovame Henrique Bresan Schiavon. [inedito].

NAKED, Gustavo Montes; LUCCA, Sergio Roberto de. Desenvolvimento e aplicação de modelo integrado de certificação do sistema de gestão ambiental para empresas con mais de um site. Disponivel em: Lhttp//www.colatina.com.br/br/artigos/cert_ambiental/cert_amb_01.asp> Acesso em 20 nov. 2002.
} 
Na Rio-92 foram elaborados os seguintes documentos: Declaração do Rio sobre Meio Ambiente e Desenvolvimento, Agenda 21, Princípios para a Administração Sustentável das Florestas, Convenção da Biodiversidade, Convenção sobre a mudança de Clima, além de reafirmação do conceito de desenvolvimento sustentável".

Vale ressaltar que a adoção deste conceito não significou a eliminação das divergências entre organizações governamentais, não governamentais e privadas. Pode-se perceber que houve um consenso para atingir os objetivos centrais desta nova fase: a preocupação ambiental focada no processo de produção e consumo de modo que os danos ambientais sejam evitados nas suas raizes. De sorte que, a Rio-92, influiu na criação de normas e padrōes de controle de qualidade que garantissem a preservação ambiental.

O Estado, assim, tem respondido através da formulação de políticas públicas tendentes a convencer os agentes econômicos a considerar os custos sociais da degradação ambiental em seus cálculos privados. Tais políticas podem ser expressas através de dois mecanismos fundamentais: a regulação direta ("direct regulatory approach") e a adoção de incentivos e instrumentos de natureza econômica que tenham a capacidade de induzir o comportamento desejado ${ }^{5}$.

\subsection{Regulação Direta}

Através da regulação direta são estabelecidos limites legais às externalidades negativas, os quais tendem a ser observados em razão da existencia de um sistema de fiscalização e de penalização aos eventuais agentes econômicos infratores.

O nivel máximo tolerável das externalidades é estabelecido mediante um processo de negociação social, seja através da representação popular direta no Poder Legislativo, ou arbitrado pelo órgão ambiental público competente, buscando-se, em qualquer hipóteses, um equilíbrio entre os objetivos de desenvolvimento econômico e social de curto ou médio prazo e o nível de comprometimento dos recursos ambientais, de tal modo que possam ser mantidas as possibilidades e as condições de desenvolvimento no longo prazo ${ }^{6}$.

\footnotetext{
"Importante destacar que, em 1987, fó aprovado e divulgado pela ONU o relatório "Nosso Futuro Comum", também conhecido como "Relatório Brundtiand", o qual relacionou 109 recomendaçós destinadas a concretizar os propósitos da Conferência de Estocolmo e deu enfase à discussão ema torno do desenvolvimento sustentável. Na verdade, a Comissa Mundial para o Desenvolvimento do Meio Ambiente listou uma série de defnições para o conceito de desenvolvinento sustentável; contudo, a que vem sendo niais repetida e considerada é: "desenvolvimento sustentável significa que as açöes presentes não devem comprometer a capacidade das geraçöes futuras de satisfazer suas necessidades, com base em que o valor total dos bens disponíveis, tanto produzido pelo homem como aqueles encontrados na natureza, deve permanecer constante de uma geraçäo para a outra". cf. NAKED; LUCCA, op. cit.

"CARNEIRO, Ricardo. Direito ambiental: Una abordagem economica. Rio de Janeiro; Forense, 2001, p. 73. Ibid., p. 734 .
} 
Embora os economistas prefiram os mecanismos baseados nos incentivos de mercado, acreditando que sua eficácia é maior do que a regulação direta, deve-se compreender que os instrumentos econômicos são apenas parte de um arsenal de medidas destinadas à concretização da política econômico-ambiental ${ }^{7}$.

Nesse contexto, sua relação desses com a dinâmica da política regulatória centrada no comando e controle é de absoluta complementaridade, na medida em que traduzem a motivação econômica que a mera disciplina de comportamentos não consegue enfocar.

\subsection{Instrumentos Econômicos}

A utilização de mecanismos econômicos na gestão ambiental deve, pois, sempre se dar em sintonia com a política de regulação direta. Dessa forma, por exemplo, a idéia da cobrança de um preço pela utilização de um curso d'água como corpo receptor de residuos industriais não pode prescindir da regra de controle que defina um padrão de qualidade no ponto em que ocorre a emissão no rio.

Somente assim a indústria poderá se ajustar e ainda terá, posteriormente, estímulos econômicos para implementar reduções adicionais da poluição, desde que para tanto haja tecnologia disponivel e valores de cobrança inversamente proporcionais à qualidade do efluente (quanto melhor a qualidade, menor o valor a ser pago) . $^{8}$

Não obstante as diferentes classificações oferecidas pela doutrina econômica sobre a matéria, pode-se identificar como principais as seguintes categorias de instrumentos econômicos: tributos ambientais, cobrança pelo uso de recursos ambientais, subsídios públicos, sistemas de devolução de depósitos ${ }^{9}$, licenças ou créditos negociáveis e seguro ou caução ambiental ${ }^{10}$.

Por fim, à luz de que a degradação do meio ambiente, surge em razão do fato de que boa parte dos recursos ambientais constituir-se bens de acesso livre. Aos quais, não é atribuído um preço de uso, de forma que os custos privados da atividade produtiva passam desalinhados em relação aos custos sociais.

\footnotetext{
? Tbid., p. $76-7$.

"Tbid., p. 77.

- Os chamados sistemas de devolução de depósitos (deposit-refund systems) envolvem a idéia do paganetato pelo consumidor de um valor adicional incidente sobre o preço final do produto, o qual lhe é de alguma forma reembolsado posteriormente caso o bem, sua embalagem ou seus residuos seja devidamente retornado por intermédio de algum ponto ou sistema autorizado de coleta, evitando a poluição, o aćmulo de lixo e a maior parte dos custos necessários à sua remoção.

1 Ibid., p. 77
} 
Exige-se que, para correção das falhas ou ineficiências do mercado, a intervenção do Poder Público, seja regulando diretamente o comportamento dos agentes, seja induzindo sua ação através de instrumentos econômicos que os estimulem a se adequarem a padrões aceitáveis ${ }^{1 !}$.

Assim, pode-se afirmar, que a atuação estatal, além de impor condutas, influencia o surgimento espontâneo de práticas responsáveis. Práticas baseadas em mecanismos que sugerem a negociação e a concertação social a implementação de determinadas soluçōes de índole privada para o problema do desenvolvimento sustentável, ao lado de procedimentos ligados ao senso de autodisciplina do mercado, tais como a marca de certificação.

\section{Marcas de Certificação Ambiental}

A propriedade intelectual, uma das expressões da atividade do Estado regulando a economia, refere-se a um agrupamento de institutos jurídicos que regulam os usos de tipos diferentes de idéias e insígnias (bens imateriais). Engloba, dentre outros assuntos, a lei de direito autorais a lei de propriedade industrial (marcas e patentes) e a repressão à concorrência desleal ${ }^{12}$.

Há, na proteção às marcas, respeito à três ordens de interesses: do consumidor (em identificar o produto que possua as características que deseje), dos concorrentes (em não perder mercado para alguém que utilize meios desleais de concorrência) e do produtor (em usufruir da boa fama de seu produto).

Isso porque, atualmente, a marca é entendida como uma indicação útil à regulamentação da atividade econômica e de defesa do direito do consumidor, composta por um nome, termo, signo, sinal, símbolo ou uma combinaçáo desses elementos, para identificar ou garantir a qualidade de bem ou serviço de um titular, de modo a distingui-lo dos de outro coletiva ou individualmente ${ }^{i 3}$.

\footnotetext{
11 Ibid., p. 87.

I2 BASSO, Maristela. O Direito internacional da propriedade intelectual. Porto Alegre: Livraria do Advogado, 2000, p. 53 . Importante esclarecer que a propriedade em geral pode ser de bens materiais e imateriais, a propriedade intelectual, por sua vez, preocupase com produtos do intelecto, nesse sentido, afirmarse que protege bens imateriais. Nesse sentido, a propriedade intelectual é o direito exclusivo de propriedade sobre formas intangiveis de criaçäo e sobre os resultados concretos de suas aplicaçōes. Assim, o direito de marcas pode ser usado para evitar que terceiros usem uma marca que possa levar o consumidor a confundila com outra similar, mas não impede que outros possam fazer o mesmo produto ou vendêto sob uma marca que não gere essa confusão. cf. FROTA, Maria Stela Pompeli Brasil. Proteçäo de patentes de produtos farmacêtuticos: O caso brasileiro. Brasilia: IPRI, 1993, p. 134.

"s. ef SCHIAVON, Giovanne Henrique Bressan. Proteção Juridica Internacional e Comunitána às Marcas de Produto e Serviço: O caso do Mercosul. Londrina, 2003. Dissertaçäo (Mestrado em Direito Negocial) - Universichade Estadual de Londrina.
} 
Gonçalves explica que uma marca só pode distinguir por duas formas: ou garantindo a presença de determinada qualidade ou garantindo a proveniência do produto marcado de uma mesma fonte de origem ${ }^{14}$. Assim, vislumbra-se duas grandes espécies de marca: a).- de certificação; e, b).- de produto ou de serviço.

Marca de certificação é um nome, termo, signo, símbolo ou uma combinação desses elementos, que identificam produtos ou serviços, que é utilizada no produto ou serviço para identificar que esse possui alguma qualidade aferida por um órgão externo (estatal ou privado).

Carneiro, destaca que, apesar das incoerências do atual modelo de consumo, a prática empresarial tem demonstrado ser possível - de acordo com determinados parâmetros - que o mercado desempenhe alguma função de instância regulatória para os problemas relacionados ao meio ambiente ${ }^{15}$.

Assim, por exemplo, nos casos de um produto (ou serviço) que adote uma determinada técnica, ou seja parte de um contexto maior, poderá ostentar uma marca que certifique tal especificidade atestada por: a) um órgão público (por exemplo o selo do INMETRO ${ }^{16}$, o qual confere fé pública sobre a observância de alguma norma); ou b) por um órgão privado (por exemplo o selo $\mathrm{ISO}^{17}$, o qual atesta a observância de determinado padrão de qualidade).

Marca de produto ou de serviço, por sua vez, é um nome, termo, signo, símbolo ou uma combinação desses elementos, que distinguem produto ou serviço, de um produtor, vendedor ou profissional de modo coletivo ou individual. Essa, desempenha a função comercial individualizadora, através da associação de uma imagem exclusiva ao produto, tornando-o único à vista do consumidor.

\footnotetext{
it cf. GONCALVES, Lux́s M. Couto. Direito de marcas. Coimbra: Almedina, 2000.

1. CARNEIRO, Ricardo. Direito ambiental: Uma abordagem econômica. Rio de Janeiro: Forense, 2001 , p. 91.

16 O Instituto Nacional de Metrologia, Normalizaça e Qualidade Industral - Inmetro - é uma autarquia federal, vinculada ao Ministério do Desenvolvimento, Industria e Comércio Exterior, que atua como Secretaria Executiva do Conselho Nacional de Metrologia, Normalização e Qualidade Industrial (Conmetro), colegiado interministerial, que to órgão normativo do Sistema Nacional de Metrologia, Normalização e Qualidade Industrial (Sinmetro). Disponivel em <http:/) Www.inmetrogow.br/inmetro/oque asp? Acesso em 03 dez. 2002.

1" A "Tntemational Organization for Standardization" - ISO (organizaça internacional para padronizaçăo) é uma organizaçấo näogovernamental fundada em 1947, com sede en Genebra e que congrega os orgäos de normalização de mais de 100 paises, (cf. CARNEIRO, op. cit. p. 93). Nessa organização, o Brasil é represcntado pela Associaçäo Brasileira de Normas Técnicas - ABNT Os padrões são desenvolvidos pelos grupos técnicos e votados pelos Estados membros; uma vez aprovados, săo incorporados ao conjunto normativo internacional. (cf. 〈http:/www.ansi,org/public/isol4000/fac/ faq c.html Acesso cm I dez. 2002).
} 
Importante destacar que o motivo que anima a marca de certificação é diferente do da marca de produto e de serviço. Embora, as marcas sempre confiram uma identidade ao produto/serviço, a marca de certificação exerce primordialmente a função de garantia de qualidade. Essa, obriga a todos os produtores/vendedores (ou prestadores do serviço) a se sujeitarem a um padrão de qualidade para poder ostentá-la. Ao passo que, a marca de produto ou de serviço, confere a identidade ou a indicação de que o produto/serviço tem origem.

Em regra, as marcas de certificação identificam de modo coletivo, enquanto que as marcas de produto e de serviço distinguem de modo individual. Ou seja, cada produto terá a sua marca de produto ou de serviço ao passo que vários produtores poderão ostentar a mesma marca de certificação, a qual, inclusive pode ser imposta de modo obrigatório para figurar ao lado da marca de produto ou de serviço ${ }^{18}$.

Não é exagerado afirmar que, as marcas de produto ou de serviço são o maior bem de uma empresa, sobrevivendo até mesmo a produtos específicos e instalações fisicas da empresa. Pois, por trás de cada marca vislumbra-se uma série de consumidores leais. Note-se que, o direito de propriedade intelectual, desenvolvido, através da consolidação do capitalismo industrial e do próprio Estado moderno, foi aprimorado em decorrência de duas necessidades: o fomento do livre-mercado; e, legitimar, via a intervenção estatal, o desenvolvimento da atividade econômica ${ }^{19}$.

Essas necessidades reproduzem, então, a tensa coexistência entre o direito econômico e o direito comercial. No direito comercial a atuação estatal é no sentido de garantir os negócios, os agentes são livres para exercer sua autonomia individual. Enquanto que no direito econômico é o direito da intervenção estatal, junto ao qual, o Estado age na posição de comando intervindo nos negócios seja em âmbito interno, seja em âmbito internacional. A partir dessa tensão, estruturou-se a atuação estatal no controle e regulação das atividades econômicas.

\footnotetext{
13 Domingues esclarece que existem marcas de produto e de serviço de uso individual e de uso coletivo. A marca de produto ol de serviço coletiva é a que pertence a coperativas, sindicatos e associaçoes outras que constituem uma individualidade juridica própria e autonoma, uma pessoa juridica que possti vida distinta dos seus membros componentes. Assim, o titular da marca coletiva é uma pessoa juridica singular embora sen uso seia coletivo. Enquanto que a marca de produto ou de serviço individual é um dicito singular de propriedade, ou seja, é utilizada por umá única pessoa para seu uso exclusivo (DOMINGUES, Douglas Gabriel. Marcas e expressöes de propaganda. Rio de Janeiro: Forense, 1984 , p. 1789.

${ }^{19}$ DEL NERO, Patricia Anrelia. Propriedade Intelectual: a tutela juridica da biotecnologia. São Paulo: Revista dos Tribunais, $1998, \mathrm{p}$. 31, afirma que o desenvolvimento do direito de propriedade intelectual é fruto da forma moderna da propriedade (direito exclusivo, que em caráter permanente, se tem sobre a coisa que pertence a um titular) que adequada o mundo burguês e à economia capitalista, consagrase em assegurar o dominio, não apenas sobre as coisas en si, mas, sobretudo, sobre todas as possibilidades criação do valor economico, entre elas a propria capacidade intelectual e criativa do homem, que no capitalismo industrai, torna-se mercadoria.
} 
Como descrito supra, a RIO-92, impulsionou propostas de harmonização internacional de normas de gestão do meio ambiente, rotulagem e ciclo de vida dos produtos. Nessa perspectiva, vem se acentuando a tendência de implementação de mecanismos de autocontrole e auto-regulação do mercado, com o surgimento de processos de rotulagem ecológica ("ecolabelling") e de certificação ambiental, capazes de, por um lado, destacar os empreendimentos e os produtos que cumprem com os padrões de qualidade exigidos e, por outro, discriminar as atividades que não se adaptam às novas exigências ambientais ${ }^{20}$.

Nos países desenvolvidos esses instrumentos já estão regulando o acesso aos mercados para uma vasta gama de produtos internos ou provenientes do exterior, surgindo nos últimos anos vários "selos verdes" e rótulos ecológicos, dentre os quais destacam-se: o Green Seal, o Nutriclean e o Freshnet Envirommental Choice Australia (Austrália); o Eco Mark (Japão); o Blue Engel Blauer Engel e o Ökotex (Alemanha); o NF Environment (França); e, o Ecolable (União Européia) ${ }^{21}$.

No Brasil, observa-se o reconhecimento de três espécies principais de marcas de certificação, a saber: o ISO 14000, a certificação florestal e a certificação agrícola. No limitado espaço desse artigo, deixa-se de apresentar a certificação florestal e agrícola e concentra-se no sistema ISO 14000.

\subsection{ISO 14000}

Para auxiliar a RIO-92, a International Organization for Standardization (ISO), uma organização não governamental, que coordena o desenvolvimento e implementação de padrões internacionais de modo espontâneo, reuniu um grupo para estudar padrões de atuação empresarial que estariam de acordo com o conceito de desenvolvimento sustentável.

A ISO, então constituiu um Strategic Action Group on the Environment (SAGE) - grupo estratégico sobre meio ambiente - imbuído de um compromisso de formular propostas de padrões para aprimorar a performance ambiental da comunidade empresarial, ocupouse de investigar se seria necessária uma norma especial para tratar da questão ambiental ou se tal aspecto deveria ser adotado na própria série ISO 9000. Eis que, o SAGE, identificou o risco potencial de que a inexistência de padrões poderia constituir-se em barreira técnica (embora não intencional) ao comércio internacional ${ }^{22}$.

\footnotetext{
2 CARNEIRO, Ricado. Direito ambiental. Uma abordagem económica. Rio de Janeiro. Fotense, 2001 , p. 92.

21 CARNEIRO, Ricardo. Direito ambiental: Uma abordagem económica. Rio de Janeiro: Forense, 2001, p. 93.

23 cf. VIANA, Ana Carolina; NOGUEIRA, Jorge Madeira. ISO 14000: Comercio e Meio Ambiente. Disponivel em: <http:/www.unb.br/ih/eco/nepama2k/NEPAMA003.doc/Acesso en 26 nov. 2002. CAVALCANTI FILHO, Gabriel de Oliveira. A ISO 14000 e o direito ambiental em evoluçäo: Concretizaçăo do desenvolvimento sustentavel atraves da qualidade ambiental. In: ERETAS, Vhadimir de Passos (org) Direito ambiental em evolução. n. 2, Curitiba: Juruá, 2000. p. 106-110.
} 
Nesse sentido, o SAGE recomendou a formação do Comitê Técnico do ISO de número 207, para elaborar uma norma técnica distinta da série ISO 9000. Assim, em março de 1993, o Comitê Técnico 207, tendo por base a norma britânica BS 7750 e as diretrizes da RIO-92, traçou normas para um sistema internacional de gerenciamento ambiental, compondo a série ISO $14000^{23}$.

Finalmente, na IV reunião do CT-207/ISO14000, realizada em julho de 1996, no Brasil, foram aprovadas as seguintes normas de gestão ambiental ${ }^{24}$ :

a) ISO 14001: Sistemas de Gestão Ambiental: Especificação e Diretrizes para Uso;

b) ISO 14004: Diretrizes Gerais sobre Princípios, Sistemas e Técnicas de Apoio;

c) ISO 14010: Diretrizes para Auditoria Ambiental: Princípios Gerais,

d) ISO 14011:Diretrizes para Auditoria Ambiental: Procedimentos de Auditoria e

e) ISO 14012: Diretrizes para Auditoria Ambiental: Critérios de Qualificação para Auditores Ambientais ${ }^{25}$.

Da série 14000 , a norma da ISO com mais ampla aplicação é seguramente a ISO 14001, que contém os requisitos para a implantação voluntária de um Sistema de Gestão Ambiental (SGA) - "Environmental Management System” - em qualquer segmento econômico, com base na estrutura organizacional, no planejamento de atividades, na definição de responsabilidades, nas práticas, procedimentos, processos e manutenção da política ambiental do empreendimento ${ }^{26}$.

Dessa forma, a implementação do SGA pressupõe algumas exigências ambientais básicas, no que se refere à atuação dos fornecedores de matérias-primas, aos processos e métodos produtivos, à qualidade final dos produtos e serviços, ao cumprimento e adequação à legislação ambiental, além da difusão, por todo o quadro de pessoal do empreendimento, das informações, diretrizes e metas estratégicas de gerenciamento ambiental ${ }^{27}$.

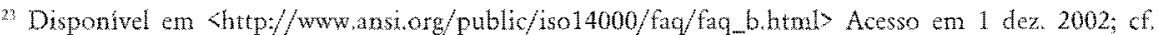
VIANA, Ana Carolina; NOGUEIRA, Jorge Madeira. ISO 14000: Comércio e Meio Ambiente. Disponivel em: Lhttp//www unb.br/ih/eco/nepama2k/NEPAMA003.doc Acesso em 26 nov. 2002.

${ }^{27}$ As normas da ISO 14000 para Rotulagem Ambiental (a ISO 14020, a ISO 14021 e a ISO 14022), a para Avaliação do Desempenho Ambiental (a ISO 14031) e as para Avaliação do Ciclo de Vida (ISO 14040 e ISO 1.4041) ainda não forma publicadas, cf. VIANA, Ana Carolina; NOGUEIRA, Jorge Madeira. ISO 14000: Comércio e Meio Ambiente. Disponivel em: $<$ http:/www.unb.br/ih/eco/nepama2k/ NEPAMA003.doc $>$ Acesso em 26 nov. 2002

25 A tradução equivalcnte para o portuguès das normas da série ISO 14000 , chamadas, de acordo corn a norma a que se referem, de NBR ISO 14001, NBR ISO 14004, e assim por diante, forara publicadas pela ABNT - Associaçào Brasileira de Normas Técnicas.

CARNETRO, op. cit, p. 94.

27 Ibid.
} 
Viana e Nogueira reúnem como razões aptas a levar um empreendimento a optar pela ISO 14000: a proliferação de diferentes normas voluntárias de gestão ambiental, internas aos próprios empreendimentos, nacionais (como a BS 7750 do Reino Unido) ou regionais (como a EMAS - Eco-Managements and Audit Scheme da União Européia); a exigência de clientes estrangeiros e do próprio país; o maior acesso a investimentos e os beneficios em termos de eficiência dos empreendimentos ${ }^{28}$. Até para os governos é interessante que os empreendimentos optem pela ISO 14000, pela maior facilidade que esses teriam de fiscalizar a obediência à legislação ambiental.

Vale destacar, no entanto, que a necessidade de certificação de processos e empreendimentos ou de rotulagem ambiental de produtos, como requisitos para o acesso e a competição nos mercados, transforma muitas vezes esses instrumentos em verdadeiras barreiras ou entraves ao comércio internacional, criando obstáculos concorrenciais a determinados empreendimentos, sobretudo aos de pequeno e médio portes, face aos custos relacionados à certificação e à implantação de sistemas de gerenciamento ambiental ${ }^{29}$.

Por fim, a obtenção da certificação possibilita às empresas demonstrar que são "ecologicamente corretas" e a utilizar essa conquista como um elemento de marketing, tornando-se também um diferencial de mercado.

\section{Conclusão}

As ilimitadas necessidades humanas aliadas em face aos limitados recursos ambientais, obrigam a sociedade a disciplinar o uso desses. De modo que, desenvolvimento sustentável significa que as ações presentes não devem comprometer a capacidade das gerações futuras de satisfazer as suas próprias necessidades.

E certo que seja impondo, seja indicando condutas o Estado continua sendo o principal organismo de controle social. Contudo, o Estado, isolado não consegue impor o controle a todas as situações de utilização dos recursos ambientais. Assim, a sociedade participa através de mecanismos de autocontrole de sua própria atuação.

A marca de certificação conceituada como um nome, termo, signo, símbolo ou uma combinação desses elementos, que identificam produtos ou serviços, utilizados em produto ou serviço para identificar que esse possui alguma qualidade aferida por um órgão externo (estatal ou privado).

Esse instituto do direito foi apresentado como um dos mecanismos aptos a ser utilizado para fomentar o desenvolvimento sustentável. A sociedade compete eleger padrões desejáveis de atuação ambiental e também supervisionar a observância desses padrões atestada pelo sinal aposto ao produto.

\footnotetext{
2* VIANA, Ana Carolina; NOGUEIRA, Jorge Madeira. 150 14000: Comércio e Meio Ambiente. Disponivel em: $\langle$ http:/www unb.br/ih/eco/nepama2k/NEPAMA003.doc) Acesso em 26 nov. 2002.

29. Arualmente, mais de 10.000 enzresas já foram certificadas no mundo, enquanto que mais de 200 empresas brasileiras conseguiram implementar seus sistemas de gestão ambiental e, conseqüentemente, receberam a certificaçăo segundo os critérios estabelecidos pela Norma ISO 14001 (cf. MORAIS, Luciana. Certificą̧a ambiental chega ao turismo. Disponivel em: 〈http:/ wwwpholcom,br/news_eco/ eco/news/messages/104.htm> Acesso em 2 nov. 2002).
} 
Em um mundo no qual as disputas por mercados são cada vez mais violentas, com a intensificação dos blocos regionais de integração e a rotineira imposição de restrições de caráter não tarifário ligadas a questões ambientais, a rotulagem ecológica e a certificação ambiental representam para as empresas exigencias adicionais na luta por espaços comerciais, cada vez mais restritos e exigentes quanto a padrões de segurança e qualidade de produtos e serviços.

\section{Bibliografia}

BASSO, Maristela. O Direito internacional da propriedade intelectual. Porto Alegre: Livraria do Advogado, 2000.

BRUNDTLAND, Gro Harlem. Desafios Ambientais dos anos 90. Nossa Responsabilidade para as futuras gerações. Trad. Yuri Frederico Dutra. Revisão técnica Giovanne H. B. Schiavon [inédito].

CARNEIRO, Ricardo. Direito ambiental: Uma abordagem econômica. Rio de Janeiro: Forense, 2001.

CAVALCANTI FILHO, Gabriel de Oliveira. A ISO 14000 e o direito ambiental em evolução: Concretização do desenvolvimento sustentável através da qualidade ambiental. In: FREITAS, Vladimir de Passos (org.) Direito ambiental em evolução. n. 2, Curitiba: Juruá, 2000. p. 99-111.

DEL NERO, Patrícia Aurelia. Propriedade Intelectual: a tutela jurídica da biotecnologia. São Paulo: Revista dos Tribunais, 1998.

DOMINGUES, Douglas Gabriel. Marcas e expressões de propaganda. Rio de Janeiro: Forense, 1984.

FROTA, Maria Stela Pompeu Brasil. Proteção de patentes de produtos farmacêuticos: O caso brasileiro. Brasília: IPRI, 1993.

GERHARDT, Rodrigo. Marcas consagradas lançam versão "eco". Folha de São Paulo, São Paulo, 19 set. 2002, Equilíbrio, p. 6-8.

GONÇALVES, Luís M. Couto. Direito de marcas. Coimbra: Almedina, 2000. KAPLAN, Morton A.; KATZENBACH, Nicholas de B. Fundamentos políticos do direito internacional. Trad. Sigrid Faulhaber Godolphim; Waldir da Costa Godolphim. Rio de Janeiro: Zahar, 1964.

LIMA, Marcelo. Na onda verde. Folha de São Paulo, São Paulo, 07 jul. 2002, Revista da Folha, p. 28-29.

MORAIS, Luciana. Certificação ambiental chega ao turismo. Disponível em: <http: /www.phol.com.br/news_eco/eco/news/messages/104.htm>Acesso em 2 nov. 2002. NAKED, Gustavo Montes; LUCCA, Sérgio Roberto de. Desenvolvimento e aplicação de modelo integrado de certificação do sistema de gestão ambiental para empresas com mais de um site. Disponível em: $\langle$ http:/ www.ecolatina.com.br/br/artigos/ cert_ambiental/cert_amb_01.asp> Acesso em 20 now. 2002.

SCHIAVON, Giovanne Henrique Bressan. Proteção Jurídica Internacional e Comunitária às Marcas de Produto e Serviço. Londrina, 2003. Dissertação (Mestrado em Direito Negocial) - Universidade Estadual de Londrina.

VIANA, Ana Carolina; NOGUEIRA, Jorge Madeira. ISO 14000, Comércio e Meio Ambiente. Disponível em: <http//www.unb.br/ih/eco/nepama2k/ NEPAMA003.doc>Acesso em 26 nov. 2002. 